\title{
Tsafon
}

Revue d'études juives du Nord

$78 \mid 2019$

L'antijudaïsme dans l'Antiquité

\section{Maisonneuve (de la) Dominique et Hebbelinck Thérèse, Histoire du SIDIC. Service d'Information et de Documentation Juifs-Chrétiens}

\section{Olivier Rota}

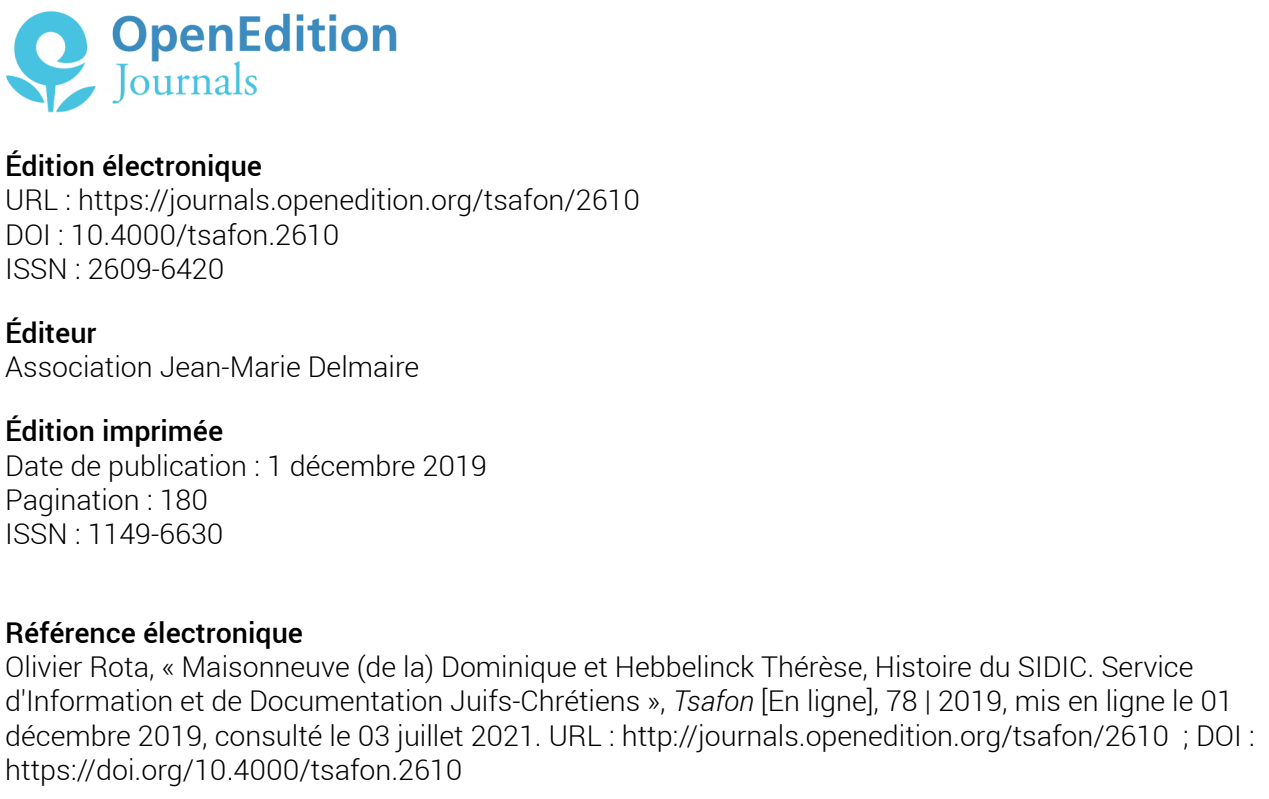

Ce document a été généré automatiquement le 3 juillet 2021

Tsafon. Revues d'études juives du Nord 


\title{
Maisonneuve (de la) Dominique et Hebbelinck Thérèse, Histoire du SIDIC. Service d'Information et de Documentation Juifs-Chrétiens
}

\author{
Olivier Rota
}

\section{RÉFÉRENCE}

Paris, Parole et Silence, 221 p., $20 €$

1 Disons-le d'emblée : l'ouvrage relève plus du témoignage que de l'analyse historique ce qui ne retranche rien à sa qualité et à son intérêt, bien au contraire. Le lecteur y trouvera introduit le contexte conciliaire dans lequel quelques religieuses de Sion se sont impliquées en faveur d'un renouvellement de l'enseignement de l'Église sur les Juifs, et d'où naquit le SIDIC, rattaché au Secrétariat pour l'Unité des chrétiens. À Paris, le Centre pour Israël, dirigé par les sœurs, connaît un virage difficile dont attestent les auteurs : « la teshouva, le retournement, ne fut pour un grand nombre des sœurs ni facile ni rapide ", car elle impliquait d'abandonner tout prosélytisme. S. Bénédicte et $\mathrm{S}$. Louise-Marie produisent toutefois un renouveau au sein de leur congrégation en repensant leur relation aux Juifs et en promouvant une conversion des chrétiens. Le SIDIC-Paris, qui succède officiellement au CPI en 1969, a porté en France ce renouvellement, sans toutefois emporter l'adhésion de toutes les sœurs enseignantes de la congrégation, dont certaines ne parviennent pas à épouser le virage historique auquel invite le concile.

2 L'équipe du SIDIC, renforcée en 1977 par l'adjonction de S. Dominique, venue de Jérusalem, parvient cependant à donner le ton. L'ouvrage retrace les nombreuses aides de personnalités qui se sont mobilisées autour de ce centre, son esprit, ses programmes, 
ses collaborations, ses groupes, ses initiatives pédagogiques, pastorales et ecclésiales... jusqu'au retrait des sœurs en avril 2015.

3 Un volume riche en informations, qui permet de saisir les conditions de l'essor du SIDIC, les résistances auxquelles il a dû se confronter, mais aussi tout l'apport, essentiel, de ce qui constitua plus qu'un centre d'information et de documentation : une véritable instance de rencontre entre Juifs et chrétiens. 